\title{
Phase II study of necitumumab plus modified FOLFOX6 as first-line treatment in patients with locally advanced or metastatic colorectal
} cancer

\author{
E Elez ${ }^{1}$, A Hendlisz ${ }^{2}$, T Delaunoit ${ }^{3}$, J Sastre ${ }^{4}$, A Cervantes $^{5}$, R Varea $^{6}$, G Chao $^{7}, \mathrm{~J} \mathrm{Wallin}^{8}$ \\ and J Tabernero*,1 \\ ${ }^{1}$ Vall d'Hebron Institute of Oncology Barcelona, Spain and Universitat Autònoma de Barcelona, 08035 Barcelona, Spain; ${ }^{2}$ Institut Jules \\ Bordet, 1000 Brussels, Belgium; ${ }^{3}$ Centres Hospitaliers Jolimont, 7100 Haine Saint-Paul, Belgium; ${ }^{4}$ Hospital Universitario San Carlos, \\ 28040 Madrid, Spain; ${ }^{5}$ Biomedical Research Institute INCLIVA, University of Valencia, 46010 Valencia, Spain; ${ }^{6}$ Eli Lilly and Company, \\ 28108 Madrid, Spain; ${ }^{7}$ Eli Lilly and Company, 08807 Bridgewater, NJ, USA and ${ }^{8}$ Eli Lilly and Company, 16973 Stockholm, Sweden
}

Background: This single-arm phase II study investigated the EGFR monoclonal antibody necitumumab plus modified FOLFOX6 (mFOLFOX6) in first-line treatment of locally advanced or metastatic colorectal cancer (mCRC).

Methods: Patients received 800-mg intravenous necitumumab (day 1; 2-week cycles), followed by oxaliplatin $85 \mathrm{mg} \mathrm{m}^{-2}$, folinic acid $400 \mathrm{mg} \mathrm{m}^{-2}$, and 5-fluorouracil $\left(400 \mathrm{mg} \mathrm{m}^{-2}\right.$ bolus then $2400 \mathrm{mg} \mathrm{m}^{-2}$ over $46 \mathrm{~h}$ ). Radiographic evaluation was performed every 8 weeks until progression. Primary endpoint was objective response rate.

Results: Forty-four patients were enrolled and treated. Objective response rate was 63.6\% (95\% confidence interval 47.8-77.6); complete response was observed in four patients; median duration of response was 10.0 months (7.0-16.0). Median overall survival (OS) and progression-free survival (PFS) were 22.5 (11.0-30.0) and 10.0 months (7.0-12.0), respectively. Clinical outcome was better in patients with KRAS exon 2 wild type (median OS 30.0 months (23.0-NA); median PFS 12.0 (8.0-20.0)), compared with KRAS exon 2 mutant tumours (median OS 7.0 months (5.0-37.0); median PFS 7.0 (4.0-18.0)). The most common grade $\geqslant 3$ adverse events were neutropenia (29.5\%), asthenia (27.3\%), and rash (20.5\%).

Conclusion: First-line necitumumab + mFOLFOX6 was active with manageable toxicity in locally advanced or mCRC; additional evaluation of the impact of tumour RAS mutation status is warranted.

Colorectal cancer (CRC) is the third most common form of cancer in men and the second most common form of cancer in women worldwide (Ferlay et al, 2013). An estimated annual total of 1.4 million cases will be diagnosed, leading to $\sim 694000$ deaths per year ( $\sim 8.5 \%$ of all cancer-related deaths). Approximately, $25 \%$ of CRC cases are overtly metastatic at diagnosis, and $\sim 50 \%$ of patients will ultimately develop recurrent or metastatic disease (Van Cutsem et al, 2014).

Many phase II-III trials have investigated the addition of an epidermal growth factor receptor (EGFR) monoclonal antibody
(mAb) to a first-line FOLFOX (oxaliplatin, folinic acid and 5 -fluorouracil (5-FU)) combination in patients with KRAS exon 2 wild-type metastatic CRC (mCRC). The phase III PRIME study (Douillard et al, 2010, 2014) and the randomised phase II OPUS study (Bokemeyer et al, 2011) evaluated the FOLFOX4 regimen in combination with panitumumab and cetuximab, respectively. In these studies, objective response rate (ORR) and progression-free survival (PFS) were significantly improved with the addition of an EGFR mAb to FOLFOX4 among patients with tumours assessed as wild type at codons 12 and 13 of KRAS exon 2; in the PRIME study, a

*Correspondence: Professor J Tabernero; E-mail: jtabernero@vhio.net

Revised 4 December 2015; accepted 14 December 2015; published online 14 January 2016

(c) 2016 Cancer Research UK. All rights reserved 0007-0920/16

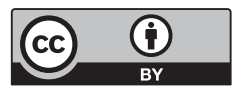


significant improvement in overall survival (OS) was also observed. Extended mutation analyses of additional tumour RAS loci (KRAS exons 3 and 4, and NRAS exons 2, 3 and 4) suggested that the efficacy benefit was further restricted to patients with tumours wild type at all screened loci (Douillard et al, 2013; Bokemeyer et al, 2015). In both the PRIME and OPUS studies, a negative effect on efficacy was reported from combining an EGFR mAb with FOLFOX4 among patients whose tumours harboured a RAS mutation (Douillard et al, 2010, 2013; Bokemeyer et al, 2011, 2015). On the basis of additional evidence showing anti-EGFR antibodies were unlikely to benefit patients with this disease whose tumours carry KRAS mutations (Amado et al, 2008; Karapetis et al, 2008), the phase III COIN trial evaluated the addition of cetuximab to oxaliplatinbased chemotherapy (oxaliplatin plus capecitabine or oxaliplatin plus fluorouracil and folinic acid) in first-line treatment of patients with advanced CRC with KRAS wild-type tumours (Maughan et al, 2011). In this trial, cetuximab increased the response rate; no evidence of benefit in PFS or OS was seen.

On the basis of these data, FOLFOX4 in combination with either panitumumab or cetuximab is recommended in Europe and the United States for the first-line treatment of patients with RAS wild-type mCRC only (NCCN).

Necitumumab (LY3012211; IMC-11F8) is a second-generation recombinant human EGFR mAb of the immunoglobulin G1 class, which demonstrates a high affinity for EGFR and blocks ligandinduced receptor phosphorylation and downstream signalling (Liu et al, 2004). In vitro studies further demonstrate that necitumumab inhibits EGFR-dependent tumour cell proliferation, and can exert cytotoxic effects in tumour cells through antibodydependent cell-mediated cytotoxicity. Necitumumab has also been shown to block tumour growth in CRC xenograft models in combination with chemotherapy (Prewett et al, 2004).

The dose and treatment schedule used for necitumumab in the current study was based on safety and pharmacokinetic data from a phase I study in 60 heavily pretreated patients with advanced solid tumours (Kuenen et al, 2010). This study established the maximum tolerated dose of necitumumab and the recommended dose for further clinical development to be $800 \mathrm{mg}$, administered intravenously (i.v.), either weekly or every second week. The major dose-limiting toxicity was grade 3 headache. The most common drug-related adverse events (AEs) were typical for this class of agent and consisted predominantly of skin reactions, headache, nausea/vomiting, and fatigue (mostly grade 1 or 2). Importantly, no hypersensitivity or infusion reactions associated with necitumumab were reported in this trial.

The present phase II study was designed to investigate necitumumab in combination with a modified version of the FOLFOX6 regimen (mFOLFOX6) and was initiated following preliminary reports (later reported in full) of encouraging activity and safety associated with cetuximab in combination with oxaliplatin-based chemotherapy (Tabernero et al, 2007; Boccia et al, 2010). Evidence at that time from small single-arm studies in chemorefractory mCRC suggested that responses to treatment with cetuximab were confined to patients whose tumours did not harbour KRAS codon 12 or 13 (exon 2) mutations (Di Fiore et al, 2007; De Roock et al, 2008; Lievre et al, 2008). These findings were later confirmed in larger randomised studies conducted in the first-line setting (Bokemeyer et al, 2011; Van Cutsem et al, 2011; Douillard et al, 2014). Accordingly, in March 2008, the protocol for the present study was amended to include evaluation of tumour mutation status at KRAS codons 12 and 13 among enrolled patients.

\section{MATERIALS AND METHODS}

Patients. Eligible patients were $\geqslant 18$ years old, with histologically confirmed locally advanced unresectable or metastatic adenocarcinoma of the colon or rectum, life expectancy $\geqslant 6$ months, and an Eastern Cooperative Oncology Group performance status (ECOG PS) of $\leqslant 2$. Patients were also required to have an EGFRdetectable or EGFR-undetectable tumour (the option of tumour biopsy was offered to patients without sufficient archived tumour tissue to allow assessment of EGFR) and at least one unidimensionally measurable target lesion ( $\geqslant 2 \mathrm{~cm}$ with conventional techniques or $\geqslant 1 \mathrm{~cm}$ with spiral computed tomography (CT) scan). Adequate haematological, hepatic, and renal function and recovery from the effects of prior therapy were also required. Key patient exclusion criteria included: prior systemic chemotherapy for locally advanced unresectable CRC or mCRC (prior adjuvant chemotherapy was allowed if progressive disease (PD) was documented $>6$ months after the end of the last cycle of adjuvant chemotherapy or $\geqslant 12$ months for oxaliplatin-containing regimens); prior radiotherapy to $>25 \%$ of bone marrow (radiation therapy as a part of standard adjuvant chemoradiotherapy for rectal cancer $>6$ months before study entry was allowed); documented and/or symptomatic brain metastases; previous therapy with mAbs or any EGFR-targeting agent; current use of chronic non-topical corticosteroid treatment for $>6$ months at doses $>10 \mathrm{mg}$ per day of prednisolone or equivalent before study entry, which in the opinion of the investigator could compromise the patient or the study; known dihydropyrimidine dehydrogenase deficiency; or acute or subacute intestinal occlusion.

The study was conducted in accordance with the ethical principles of the Declaration of Helsinki and the International Conference on Harmonisation and Good Clinical Practice. Study procedures were approved by local ethic committees, and all patients provided written informed consent.

Study design and treatment. This was an open-label, single-arm, multicentre, phase II study investigating the efficacy and safety of necitumumab in combination with mFOLFOX6 in the first-line treatment of locally advanced CRC or mCRC. A treatment cycle was defined as 2 weeks. On day 1 of each cycle, patients received necitumumab at an absolute dose of $800 \mathrm{mg}$, by i.v. infusion over $50 \mathrm{~min}$. The necitumumab infusion was followed by administration of the mFOLFOX6 regimen $\left(85 \mathrm{mg} \mathrm{m}^{-2}\right.$ i.v. oxaliplatin over $2 \mathrm{~h}$; $400 \mathrm{mg} \mathrm{m}^{-2}$ i.v. folinic acid over $2 \mathrm{~h}$; and then 5-FU, $400 \mathrm{mg} \mathrm{m}^{-2}$ i.v. bolus injection followed by $2400 \mathrm{mg} \mathrm{m}^{-2}$ continuous i.v. infusion over $46 \mathrm{~h}$ on days $1-2$ ). Dose modifications as specified in the study protocol were permitted in the event of treatment-related toxicity. Radiographic evaluation (CT or magnetic resonance imaging) of disease was performed every 8 weeks; treatment continued until documentation of PD, development of unacceptable toxicity, protocol noncompliance, or withdrawal of consent. For patients who discontinued treatment for reasons other than $\mathrm{PD}$, radiographic evaluation of disease continued at least every 3 months after discontinuation (until PD).

Endpoints and assessments. The primary endpoint was ORR, based on best response determined by investigators according to the Response Evaluation Criteria in Solid Tumors, Version 1.0 (Therasse et al, 2000). No central radiological review was carried out. Responses (complete or partial) were to be confirmed at least 4 weeks after the criteria for response were first met.

Secondary endpoints included OS, PFS, duration of response, pharmacokinetics, and safety. In addition, the association between clinical outcome (ORR, OS, and PFS) following treatment and tumour KRAS exon 2 mutation status (wild type $v s$ mutant) and EGFR mutation status and EGFR protein expression status (positive $v s$ negative) was evaluated.

Patient safety was evaluated at every treatment visit, based on reported AEs, serious AEs, physical examinations, and laboratory analyses. Adverse events were classified by type, incidence, severity, and causality. The National Cancer Institute-Common Terminology Criteria for Adverse Events, version 3.0, was used to 
grade all systemic and local AEs; all AE terms were coded using the Medical Dictionary for Regulatory Activities (MedDRA 13.0).

Tumour KRAS exon 2 and EGFR mutation screening and EGFR expression analysis were performed by Genzyme Genetics (Los Angeles, CA, USA). Mutation detection was carried out on DNA extracted from microdissected tumour sections prepared from formalin-fixed paraffin-embedded (FFPE) archival samples (following pathologist review) using an Arcturus PicoPure DNA extraction kit (Applied Biosystems, Grand Island, NY, USA). KRAS mutations (codons 12 and 13) were detected by PCR using the TheraScreen K-RAS Mutation Kit (Qiagen, Hilden, Germany). Epidermal growth factor receptor kinase domain mutation screening (EGFR exons 1821) was carried out by PCR and bi-directional sequencing (BigDye v1.1, Applied Biosystems) on a 3130 Genetic Analyzer (Applied Biosystems). Tumour EGFR expression was detected by immunohistochemistry (IHC) performed on tissue sections prepared from FFPE samples using the DAKO EGFR pharmDx IHC kit (Glostrup, Denmark). Immunostained sections were evaluated by a pathologist according to manufacturer's guidelines.

Pharmacokinetic parameters $\left(C_{\max }, T_{\max }, \mathrm{AUC}_{(0-\text { tlast })}, \mathrm{AUC}_{(0-\infty)}\right)$, $\mathrm{AUC}_{(\text {tlast- } \infty)}, t_{1 / 2}, \mathrm{CL}$, and $\left.V_{\mathrm{ss}}\right)$ were calculated using noncompartmental methods (WinNonlin 5.3, Pharsight Corporation, Cary, NC, USA) from serum concentrations over time following a single dose of $800 \mathrm{mg}$ necitumumab co-administered with mFOLFOX6 on day 1 of cycle 1 . Blood samples were collected before and immediately after the initial necitumumab infusion, and at 1, 2, 4, 24 (day 2), 72 (day 4), 96 (day 5), 144 (day 7), 168 (day 8), and 236 (day 11) hours after infusion. From cycles 2-6, additional blood samples were drawn immediately before and $1 \mathrm{~h}$ after the end of necitumumab infusion. Samples were also collected at the end of therapy and 45 days after the final necitumumab infusion.

Statistical analysis and considerations. Primary and secondary efficacy endpoints were evaluated in the modified intention to treat (mITT) population, comprising all patients who were enrolled and treated with any quantity of necitumumab or chemotherapy.

The study sample size was calculated using expected response rates of 55\% for necitumumab plus mFOLFOX6 and 32\% for mFOLFOX6 alone, based on a previously reported response rate of $32 \%$ for FOLFOX (Venook et al, 2006). Using a two-sided 95\% confidence interval (CI), it was estimated that enrolment of 40 evaluable patients would give a power of $86 \%$ to detect a significant difference in ORR between necitumumab plus mFOLFOX6 and the historical control.

The Kaplan-Meier method was used to estimate time to event data (OS, PFS, and duration of response) with 95\% CIs. Overall survival was defined as the time from the first day of therapy to the date of death; if the patient was alive at the end of the follow-up period or was lost to follow-up, OS was censored on the last date the patient was known to be alive. Progression-free survival was defined as the time from the first day of therapy until the date of PD or death, whichever was first. In the case where study treatment results in tumour regression allowing for surgical resection, the PFS analysis used the date of radiological progression determined by the regular follow-up radiological assessments following the surgical resection. If no progression was observed the patient was censored at the last radiological assessment. Duration of response was defined as the time from the day the measurement criteria were met for a complete or partial response (whichever was first recorded) until the first date of $\mathrm{PD}$ or death. Patients who neither experienced PD nor died were censored at the date of their last tumour assessment.

Exploratory subgroup analyses of ORR, OS, and PFS by tumour KRAS exon 2 mutation status and EGFR expression status were performed. The evaluation based on KRAS exon 2 mutation status was not planned in the original study protocol (6 February 2007), but was added in a protocol amendment (17 March 2008) for tumour tissue samples submitted by patients who signed an

informed consent document specific to this evaluation. No other substantive changes to the conduct of the study were made.

The database was locked for analysis on 31 March 2011. Data analyses were performed using SAS 8.2 or higher.

\section{RESULTS}

Patients and treatment. A total of 44 patients were enrolled between 01 August 2007 and 03 June 2008, at three sites in Spain and two in Belgium; all 44 enrolled patients received at least one dose of study therapy; the mITT population may therefore be considered to be equivalent to a classical ITT population. All patients discontinued study treatment, mostly due to PD $(n=18$, $40.9 \%)$ or AEs $(n=10,22.7 \%)$. Patient baseline and disease characteristics are summarised in Table 1.

All patients had a diagnosis of adenocarcinoma, originating from the colon $(65.9 \%)$ or rectum $(34.1 \%)$, and either metastatic (95.5\%) or locally advanced (two patients; $4.5 \%$ ) disease at baseline. The mean duration of disease (time from initial diagnosis to the date of first dose of any study treatment) was 5.1 months (range: $0.3-42.8$ months $)$. The majority of patients $(n=41 ; 93.2 \%)$ had a baseline ECOG PS of $0-1$.

\section{Table 1. Baseline characteristics in the ITT population}

\begin{tabular}{|c|c|}
\hline Characteristic & $N=44$ \\
\hline \multicolumn{2}{|l|}{ Sex } \\
\hline Male & $\begin{array}{l}25(56.8) \\
19(432)\end{array}$ \\
\hline \multicolumn{2}{|l|}{ Race } \\
\hline $\begin{array}{l}\text { White } \\
\text { Black }\end{array}$ & $\begin{array}{c}42(95.5) \\
2(4.5)\end{array}$ \\
\hline \multicolumn{2}{|l|}{ Age group } \\
\hline $\begin{array}{l}18 \text { to }<65 \\
\geqslant 65\end{array}$ & $\begin{array}{l}22(50.0) \\
22(50.0)\end{array}$ \\
\hline Median age, years (range) & $64.0(33-81)$ \\
\hline \multicolumn{2}{|c|}{ Duration of disease (months) } \\
\hline $\begin{array}{l}\text { Mean (s.d.) } \\
\text { Median (range) }\end{array}$ & $\begin{array}{l}5.1(9.8) \\
1.6(0.3-42.8)\end{array}$ \\
\hline \multicolumn{2}{|c|}{ ECOG performance status } \\
\hline $\begin{array}{l}0 \\
1 \\
2\end{array}$ & $\begin{array}{l}22(50.0) \\
19(43.2) \\
3(6.8)\end{array}$ \\
\hline \multicolumn{2}{|l|}{ Disease } \\
\hline $\begin{array}{l}\text { Locally advanced } \\
\text { Metastatic }\end{array}$ & $\begin{array}{c}2(4.5) \\
42(95.5)\end{array}$ \\
\hline \multicolumn{2}{|l|}{ Site of tumour origin } \\
\hline $\begin{array}{l}\text { Colon } \\
\text { Rectum }\end{array}$ & $\begin{array}{l}29(65.9) \\
15(34.1)\end{array}$ \\
\hline \multicolumn{2}{|l|}{ Tumour grade } \\
\hline $\begin{array}{l}\text { Well differentiated } \\
\text { Moderately differentiated } \\
\text { Poorly differentiated } \\
\text { Undifferentiated } \\
\text { Unknown }\end{array}$ & $\begin{array}{c}8(18.2) \\
23(52.3) \\
4(9.1) \\
0 \\
9(20.5)\end{array}$ \\
\hline \multicolumn{2}{|c|}{ Tumour EGFR expression status (IHC) } \\
\hline $\begin{array}{l}\text { Expressing } \\
\text { Negative } \\
\text { NA } \\
\text { Missing }\end{array}$ & $\begin{array}{c}16(36.4) \\
21(47.7) \\
2(4.5) \\
5(11.4)\end{array}$ \\
\hline \multicolumn{2}{|c|}{ 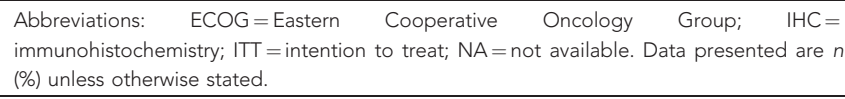 } \\
\hline
\end{tabular}


Of the 44 enrolled patients, $33(75.0 \%)$ received $\geqslant 80 \%$ of the planned doses of necitumumab, oxaliplatin, and folinic acid; 26 patients $(59.1 \%)$ received $\geqslant 80 \%$ of the planned dose of $5-\mathrm{FU}$ (Supplementary Table 1). The number of treatment delays of at least 1 week was similar across all agents. No dose reductions were

Table 2. Disease response in the ITT population and in patients grouped by tumour KRAS mutation status

KRAS evaluable patients $(N=25)^{a}$

\begin{tabular}{|c|c|c|c|}
\hline Parameter & ITT $(N=44)$ & $\begin{array}{l}\text { KRAS wild type } \\
(n=16)\end{array}$ & $\begin{array}{c}\text { KRAS mutant } \\
(n=9)\end{array}$ \\
\hline \multicolumn{4}{|c|}{ Best overall response, $n(\%)$} \\
\hline Complete response & $4(9.1)$ & $4(25.0)$ & 0 \\
\hline Partial response & $24(54.5)$ & $10(62.5)$ & $5(55.6)$ \\
\hline Stable disease & 15 (34.1) & $2(12.5)$ & $4(44.4)$ \\
\hline Progressive disease & $1(2.3)$ & 0 & 0 \\
\hline Not evaluable & 0 & 0 & 0 \\
\hline ORR, $n(\%)$ & $28(63.6)$ & $14(87.5)$ & $5(55.6)$ \\
\hline $95 \% \mathrm{Cl}$ & $47.8-77.6$ & $61.7-98.4$ & $21.2-86.3$ \\
\hline DCR, $n(\%)$ & $43(97.7)$ & $16(100)$ & $9(100)$ \\
\hline $95 \% \mathrm{Cl}$ & $88.0-99.9$ & $79.4-100$ & $66.4-100$ \\
\hline \multicolumn{4}{|c|}{$\begin{array}{l}\text { Abbreviations: } \mathrm{Cl}=\text { confidence interval; } \mathrm{DCR}=\text { disease control rate; } I T T=\text { intention to treat; } \\
\text { ORR = objective response rate. } \\
\mathrm{a}_{\text {Missing in } 19 \text { patients. }}\end{array}$} \\
\hline
\end{tabular}

required for necitumumab; $11.4 \%$ and $31.8 \%$ of patients required $\geqslant 2$ reductions to the dose of oxaliplatin and 5-FU, respectively.

Efficacy. All 44 patients in the ITT population were evaluable for the best overall response. The ORR was 63.6\% (95\% CI 47.8-77.6), including four patients $(9.1 \%)$ with a complete response and $24(54.5 \%)$ with a partial response (Table 2). An additional 15 patients $(34.1 \%)$ had stable disease as best response, resulting in a disease control rate of $97.7 \%$ (95\% CI 88.0-99.9). The median duration of response was 10.0 months (95\% CI 7.0-16.0).

A total of 30 deaths were reported; 13 patients were alive at the cut-off date (31 October 2010), and one was lost to follow-up. The median OS was 22.5 months (95\% CI 11.0-30.0). At 1- and 2-year OS, the rates were $63.6 \%$ and $42.9 \%$, respectively (Figure 1 ). In the analysis of PFS, 31 events (documented PD or death) were observed and 13 patients were censored (Figure 1); the median PFS was 10.0 months (95\% CI 7.0-12.0).

KRAS exon 2 tumour mutation status was evaluable in tumours from 25 of the 44 enrolled patients (results were not available for 19 patients, either because adequate tumour tissue was not available or the patient did not provide consent to the additional analysis). KRAS codon 12 or 13 mutations were detected in the tumours from 9 of these 25 patients (36.0\%), and the tumours from the remaining 16 patients $(64.0 \%)$ were wild type at these loci.

The ORR was higher in patients with KRAS exon 2 wild-type tumours $(87.5 \%$, 95\% CI 61.7-98.4) compared with those with KRAS exon 2 mutated tumours (55.6\%, 95\% CI 21.2-86.3), with all

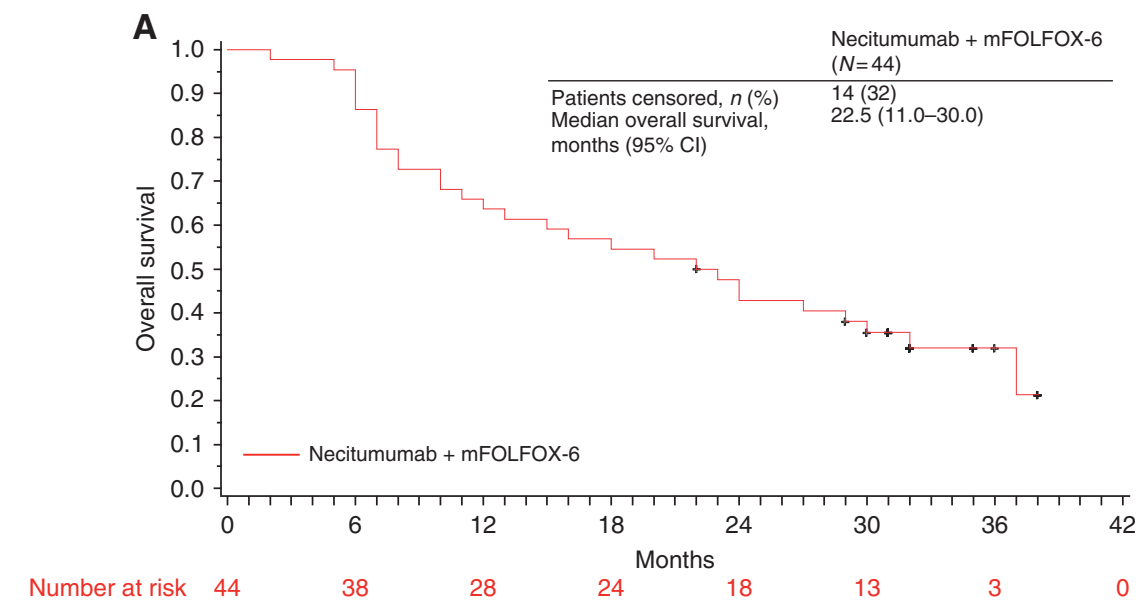

Kaplan-Meier plot showing overall survival in the intention to treat population

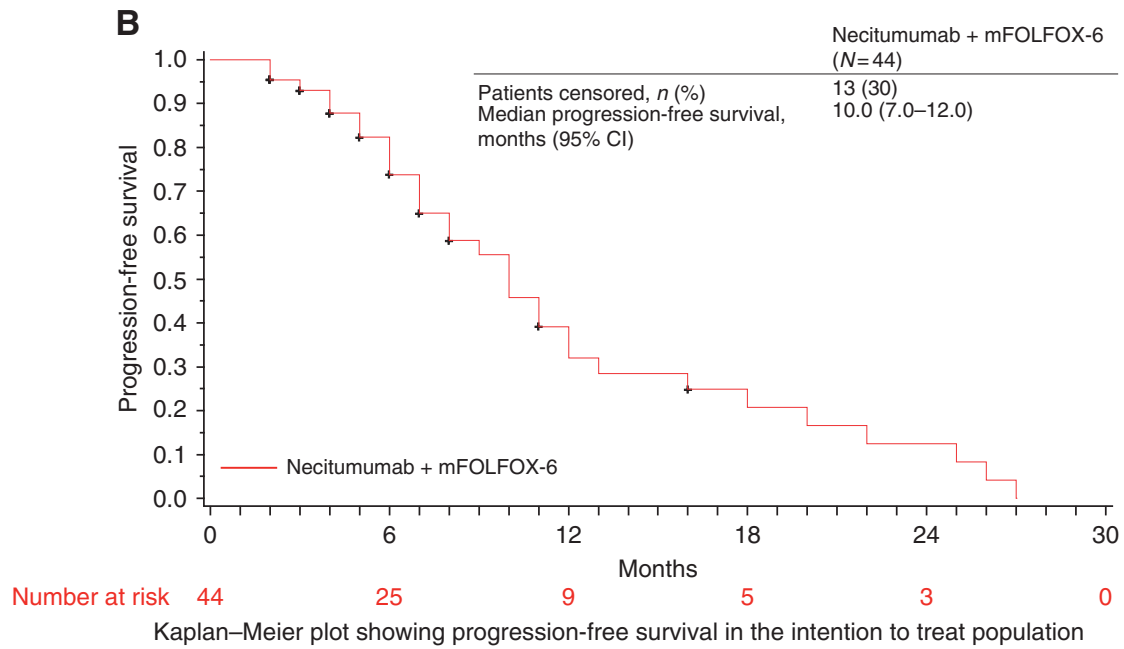

Figure 1. Overall survival and progression free survival data in the ITT population. Kaplan-Meier plots showing overall survival (A) and progression-free survival (B) in the intention to treat population. 
four complete responses reported in the study occurring in patients with KRAS exon 2 wild-type tumours. Overall survival (median 30.0 months (95\% CI 23-NA) vs 7.0 months (95\% CI 5.0-37.0)) and PFS (median 12.0 months (95\% CI 8.0-20.0) vs 7.0 months (95\% CI 4.0-18.0)) were also longer among patients with KRAS exon 2 wild-type tumours compared with those with KRAS exon 2 mutant tumours (Figure 2).

No EGFR kinase domain mutations were detected in any of the tumours from 36 patients evaluable for EGFR tumour mutation status.

Tumour EGFR protein expression status was evaluable for 37 of the 44 enrolled patients; data were missing for five patients, and the analysis was not performed for two patients. A total of 16 (43.2\%) of 37 patients had tumours that were positive for EGFR expression by IHC; 21 (56.8\%) had tumours that were EGFR negative. Overall, there were no significant differences between these subgroups for any of the efficacy parameters evaluated. The ORR was $62.5 \%$ (95\% CI 35.4-84.8) among patients with EGFR-expressing tumours and $66.7 \%$ (95\% CI 43.0-85.4) among those whose tumours were negative for EGFR expression. Median OS (25.5 months vs 24.0 months) and median PFS (11.0 months vs 10.0 months) were also similar between these subgroups.

Safety. Treatment-emergent AEs of any grade were reported in all treated patients. Grade $\geqslant 3$ events were reported in $38(86.4 \%)$ patients; the most common of these events were neutropenia (29.5\%), asthenia (27.3\%), and rash (20.5\%) (Table 3). Grade 4 AEs were reported for seven patients (15.9\%). Six of these seven patients had grade 4 AEs considered to be related to study treatment by the investigator, including four patients with grade 4 neutropenia and one patient each with sepsis and febrile neutropenia. In addition, one patient was reported with grade 4 hypocalcaemia (considered to be not related to study treatment).

Consistent with prior evidence that skin toxicity is a class effect of EGFR mAbs, 41 patients (93.2\%) experienced some form of skin or subcutaneous disorder regardless of grade or relationship to study therapy. This included five patients (11.4\%) with acneform dermatitis and 31 patients $(70.5 \%)$ with rash. Skin toxicity was

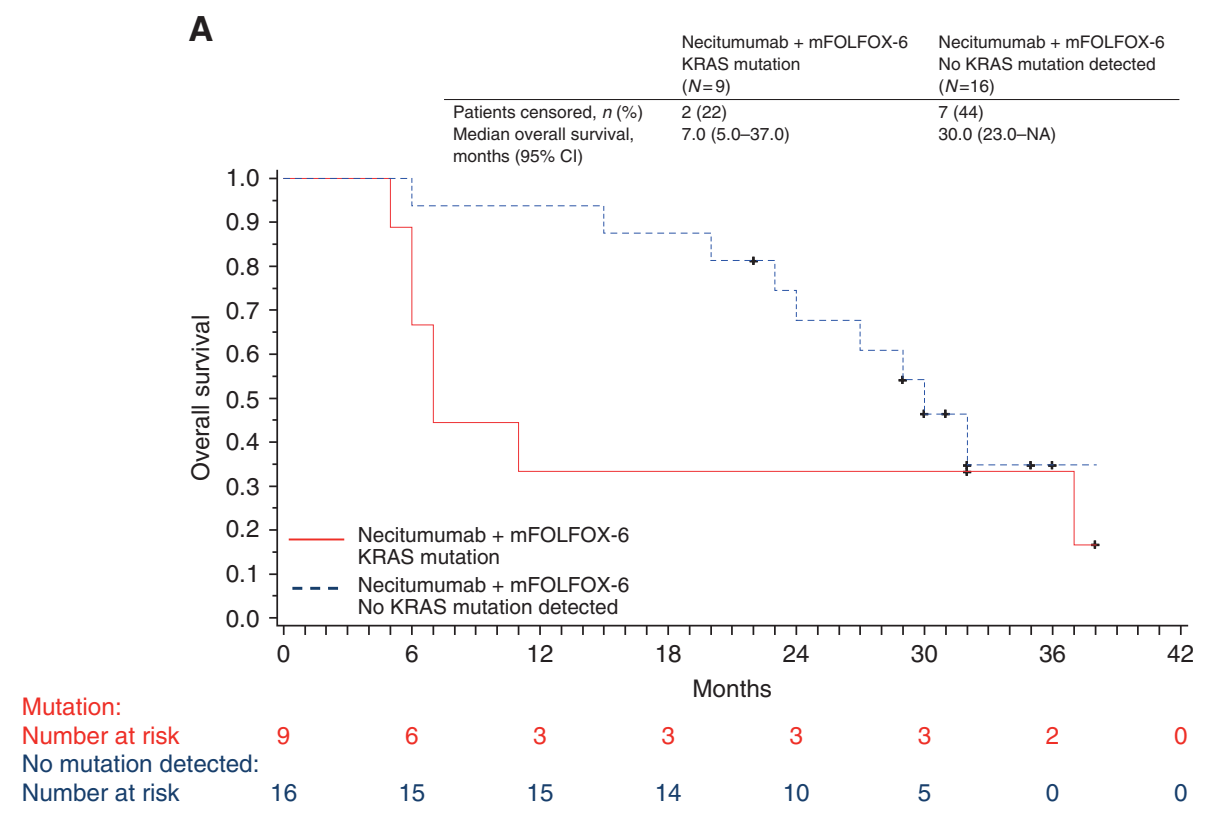

Kaplan-Meier plot showing overall survival in patients with KRAS wild-type or KRAS mutated tumours

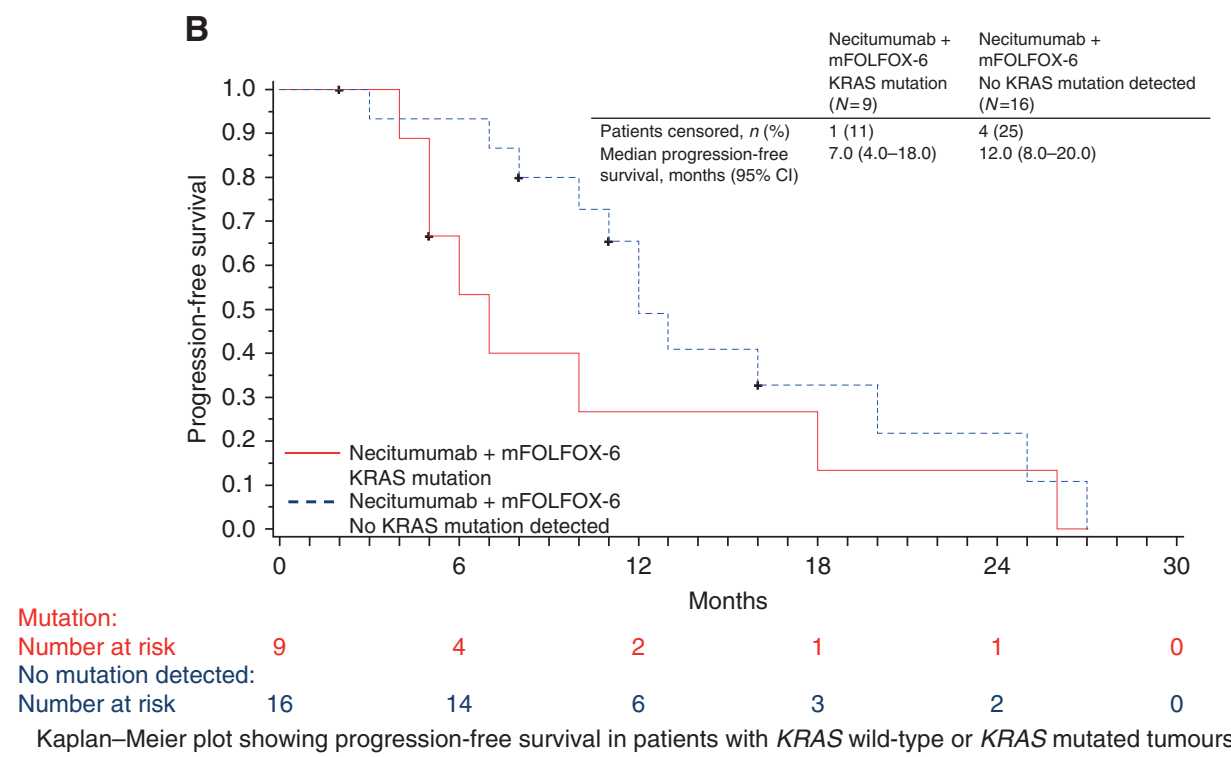

Figure 2. Overall survival and progression free survival data in the ITT population. Kaplan-Meier plots showing overall survival (A) and progression-free survival (B) in patients with KRAS wild-type or KRAS mutated tumours. 
Table 3. Treatment-emergent adverse events in the ITT population $(N=44)$

\begin{tabular}{|c|c|c|}
\hline Adverse event ${ }^{a}$ & Any grade & Grade $\geqslant 3$ \\
\hline Any & $44(100)$ & $38(86.4)$ \\
\hline \multicolumn{3}{|c|}{ Blood and lymphatic disorders } \\
\hline Neutropenia & $23(52.3)$ & $13(29.5)$ \\
\hline Anaemia & $9(20.5)$ & $1(2.3)$ \\
\hline Thrombocytopenia & $5(11.4)$ & 0 \\
\hline \multicolumn{3}{|l|}{ Eye disorders } \\
\hline Conjunctivitis & $11(25.0)$ & $1(2.3)$ \\
\hline \multicolumn{3}{|c|}{ Gastrointestinal disorders } \\
\hline Diarrhoea & $24(54.5)$ & $4(9.1)$ \\
\hline Nausea & $17(38.6)$ & $1(2.3)$ \\
\hline Vomiting & $16(36.4)$ & $3(6.8)$ \\
\hline Constipation & $13(29.5)$ & $1(2.3)$ \\
\hline Stomatitis & $8(18.2)$ & 0 \\
\hline Abdominal pain upper & $5(11.4)$ & 0 \\
\hline Dyspepsia & $5(11.4)$ & 0 \\
\hline Internal obstruction & $4(9.1)$ & $4(9.1)$ \\
\hline
\end{tabular}

General disorders and administration site conditions

\begin{tabular}{|c|c|c|}
\hline $\begin{array}{l}\text { Asthenia } \\
\text { Mucosal inflammation } \\
\text { Pyrexia }\end{array}$ & $\begin{array}{l}36(81.8) \\
19(43.2) \\
10(22.7)\end{array}$ & $\begin{array}{c}12(27.3) \\
2(4.5) \\
0\end{array}$ \\
\hline \multicolumn{3}{|c|}{ Infections and infestations } \\
\hline Paronychia & $16(36.4)$ & $1(2.3)$ \\
\hline \multicolumn{3}{|l|}{ Investigations } \\
\hline $\begin{array}{l}\text { Weight decreased } \\
\text { Weight increased }\end{array}$ & $\begin{array}{r}14(31.8) \\
7(15.9)\end{array}$ & $\begin{array}{l}0 \\
0\end{array}$ \\
\hline \multicolumn{3}{|c|}{ Metabolism and nutrition disorders } \\
\hline $\begin{array}{l}\text { Decreased appetite } \\
\text { Hypomagnesaemia }\end{array}$ & $\begin{array}{r}18(40.9) \\
5(11.4)\end{array}$ & $\begin{array}{c}2(4.5) \\
0\end{array}$ \\
\hline
\end{tabular}

Musculoskeletal and connective tissue disorders

\begin{tabular}{|l|r|c|}
\hline Back pain & $8(18.2)$ & $1(2.3)$ \\
\hline Nervous system disorders & $16(36.4)$ & $6(13.6)$ \\
\hline Paraesthesia & $13(29.5)$ & $4(9.1)$ \\
Dysaesthesia & $10(22.7)$ & $4(9.1)$ \\
Peripheral sensory neuropathy & $9(20.5)$ & $1(2.3)$ \\
Neurotoxicity & $7(15.9)$ & 0 \\
Dysgeusia &
\end{tabular}

Respiratory, thoracic, and mediastinal disorders

Dyspnoea

Skin and subcutaneous tissue disorders

Rash

Alopecia

Palmar-plantar erythrodysaesthesia syndrome

Skin fissures

Dry skin

Dermatitis acneiform

Pruritus

\begin{tabular}{l|l}
$5(11.4)$ & 0
\end{tabular}

Abbreviation: ITT = intention to treat.

${ }^{a}$ Data presented are $n(\%)$ according to preferred terms in order of system organ class coded by Medical Dictionary for Regulatory Activities for any grade occurring in $\geqslant 10 \%$ of patients or for grade $\geqslant 3$ occurring in $\geqslant 5 \%$ of patients.

grade 3 in a total of 13 patients (29.5\%), including 1 of 5 patients with acneform dermatitis (2.3\%) and 9 of 31 with rash $(20.5 \%)$. In all patients, rash and acneform dermatitis were considered at least possibly related to necitumumab. Conjunctivitis was observed in 11 patients $(25.0 \%)$, and was grade 3 in one (2.3\%); 9 of 11 patients had conjunctivitis considered at least possibly related to necitumumab (including the patient with grade 3 conjunctivitis). In addition, 10 patients $(22.7 \%)$ experienced palmar-plantar erythrodysesthesia syndrome (including two patients $(4.5 \%)$ of grade 3); necitumumab-related palmar-plantar erythrodysesthesia syndrome was reported in $7(15.9 \%)$ patients (including $1(2.3 \%)$ with grade 3).
Regarding AEs of special interest, hypersensitivity reactions were reported in three patients (6.8\%); these included one serious grade $2 \mathrm{AE}$ that was considered to be related to necitumumab, and one grade 1 and one grade $2 \mathrm{AE}$ that were considered to be related to chemotherapy. Conjunctivitis of any grade was reported in 11 patients (25.0\%); events were considered to be related to necitumumab for nine of these patients, including one with a grade 3 event. Hypomagnesaemia was reported in five patients overall; three patients experienced grade $\leqslant 2$ hypomagnesaemia considered to be related to necitumumab. Thromboembolic AEs were reported in nine patients $(20.5 \%)$, including six patients with grade 2 events and three patients with grade 3 events. Of these AEs, only one (grade 2 thrombosis in device) was considered to be at least possibly related to necitumumab.

Adverse events commonly associated with exposure to oxaliplatin-based chemotherapy included: neutropenia (52.3\%; grade $\geqslant 3,29.5 \%$ ), thrombocytopenia $11.4 \%$ (all grade 1-2), and peripheral sensory neuropathy (22.7\%; grade 3, 9.1\%). All of these AEs were considered to be at least possibly related to study therapy.

Treatment discontinuations due to AEs (primary cause) were reported in $10(22.7 \%)$ patients; these included one patient each with grade 1 thrombocytopenia, persistent grade 2 mucositis, grade 2 asthenia (worsening) with grade 2 neuropathy, grade 2 paraesthesia, grade 3 dizziness, grade 3 vomiting, grade 3 fatigue, and grade 3 asthenia. This group also included two patients who died due to an $\mathrm{AE}$ (grade 5 event), one from respiratory failure and one from intestinal obstruction. In total, there were three grade 5 treatment-emergent AEs in this study, including one additional patient with respiratory failure (including organising pneumonia). Two additional deaths, one due to intestinal obstruction and one due to respiratory failure secondary to pneumonia, were not reported as treatment-emergent AEs as they occurred $>30$ days after the last dose of study therapy. Twenty-five additional deaths occurred $>30$ days after the last dose of study therapy due to PD, including one patient whose death was deemed to be due to general health deterioration, which was considered secondary to PD. None of the reported deaths were considered to be related to any study therapy.

Pharmacokinetics. Following infusion of $800 \mathrm{mg}$ necitumumab on day 1 of cycle 1 , at least one sample for pharmacokinetic analysis was collected from 43 of 44 enrolled patients, with data available from $42(95.5 \%)$ patients. Data from three patients were excluded due to high pre-dose concentrations or limited available data points. Summary data for the non-compartmental analysis of the necitumumab pharmacokinetic parameters are shown in Supplementary Table 2 . The geometric mean $C_{\max }$ was $344 \mu \mathrm{g} \mathrm{ml}^{-1}$ (coefficient of variation $(\mathrm{CV})=46 \%$ ) following single-dose administration. The geometric means of estimated half-life and clearance were $142 \mathrm{~h}$ (range 99.8-299) and $20.3 \mathrm{mlh}^{-1} \quad(\mathrm{CV}=35 \%)$, respectively. Following multiple-dose administration ( $800 \mathrm{mg}$ every 2 weeks), geometric mean (CV\%) trough levels appeared to reach a plateau after 4-5 cycles, ranging from 59.1 (60) to 75.4 (64) $\mu \mathrm{g} \mathrm{ml}^{-1}$ (Supplementary Figure 1). Data from a pre-clinical study indicated that necitumumab was effective at or above trough concentrations of $40 \mu \mathrm{g} \mathrm{ml}^{-1}$. The median trough concentration observed in the current study exceeded this target level from cycle 3 .

\section{DISCUSSION}

This phase II study was designed to evaluate the efficacy and safety of the second-generation human EGFR mAb necitumumab in combination with mFOLFOX6 in previously untreated patients with locally advanced or metastatic CRC. The study was initiated at 
a time when other EGFR mAbs (cetuximab and panitumumab) were also in clinical development.

The majority of the 44 treated patients (95.5\%) had metastatic disease; baseline demographic and disease characteristics were generally comparable with those reported for other studies investigating chemotherapy in combination with targeted agents in previously untreated patients with mCRC (Tabernero et al, 2007; Hochster et al, 2008; Bokemeyer et al, 2009). Pharmacokinetic analysis of necitumumab largely confirmed the findings reported from the phase I study of necitumumab in patients with solid malignancies (Kuenen et al, 2010), with target trough concentrations $\left(\geqslant 40 \mu \mathrm{g} \mathrm{ml}^{-1}\right)$ achieved in most patients after three cycles of treatment. The data suggest that co-administration of mFOLFOX6 had no relevant impact on the pharmacokinetic characteristics of necitumumab.

In the ITT population, the primary endpoint of ORR was $63.6 \%$ (95\% CI 47.8-77.6); this compared favourably with the ORR of $41 \%$ (95\% CI 27-56) measured in unselected patients with mCRC receiving mFOLFOX6 alone in the randomised phase III TREE study (Hochster et al, 2008). Similarly, OS in the present study compared favourably (median 22.5 months, 95\% CI 11.0-30.0) with that reported in the TREE study (19.2 months, 95\% CI 14.2-24.9).

Response rates in the current study were also comparable with those reported in studies of cetuximab in combination with FOLFOX regimens $(44.8-72 \%)$ in unselected patients with mCRC (Tabernero et al, 2007; Bokemeyer et al, 2009; Boccia et al, 2010; Colucci et al, 2010). In addition, the secondary endpoints of OS and PFS in the current study were also comparable with those reported from these previous studies in this setting.

The effect of tumour mutations in KRAS codons 12 or 13 on the efficacy of necitumumab in combination with mFOLFOX6 was studied in 25 evaluable patients. The number of patients studied was small, and the findings should be treated with caution. However, there was a tendency towards a higher ORR $(87.5 \%$ vs 55.6\%), longer PFS (median 12.0 vs 7.0 months), and longer OS (median 30.0 vs 7.0 months) among patients whose tumours were KRAS exon 2 wild type compared with those whose tumours harboured KRAS exon 2 mutations. These findings support those from other single-arm studies of EGFR mAbs in previously treated (Di Fiore et al, 2007; De Roock et al, 2008; Lievre et al, 2008) and untreated patients (Colucci et al, 2010), which were later confirmed in larger randomised studies of first-line FOLFOX4 in combination with either cetuximab or panitumumab (Bokemeyer et al, 2011; Douillard et al, 2014). Further investigation is required to assess whether mutations at other RAS loci are negative predictors of efficacy for necitumumab in combination with a FOLFOX regimen, as has been reported for cetuximab and panitumumab (Douillard et al, 2013; Bokemeyer et al, 2015).

In further subgroup analyses, no relevant differences were reported for any of the studied efficacy endpoints in patients whose tumours were positive for EGFR expression compared with those whose tumours were negative. Thus, it appears that EGFR expression as detected by IHC is not a requirement for the efficacy of necitumumab in combination with chemotherapy, consistent with findings from other studies evaluating cetuximab (Chung et al, 2005; Folprecht et al, 2010; Brodowicz et al, 2013; Licitra et al, 2013).

The safety profile of necitumumab in combination with mFOLFOX6 was generally comparable with those reported for other EGFR mAbs when used in combination with FOLFOX regimens (Tabernero et al, 2007; Folprecht et al, 2010; Ocvirk et al, 2010; Bokemeyer et al, 2011; Brodowicz et al, 2013; Douillard et al, 2014; Wasan et al, 2014). The most common grade $\geqslant 3$ AEs were primarily class effects reflecting exposure to this treatment combination, including gastrointestinal disorders (diarrhoea 9.1\%), blood and lymphatic disorders (neutropenia, 29.5\%), nervous system disorders (paraesthesia 13.6\%), and skin toxicities (rash 20.5\%). In line with expectations for a human antibody, the incidence of hypersensitivity reactions was low: reported in only three patients (one at grade 1 , two at grade 2), the grade 2 reaction in one patient was considered to be related to necitumumab. Notably, venous thromboembolic events have previously been associated with the administration of EGFR antibodies in combination with chemotherapy (Petrelli et al, 2012). Of the eight thromboembolic events reported in the current study, none were grade $>3$ and only one was considered to be possibly related to necitumumab. There were no reports of cardiac ischaemia. Of note, the incidence of grade $\geqslant 3$ asthenia (27.3\%) was somewhat higher than generally reported in other studies of EGFR mAbs in combination with FOLFOX regimens. Adverse events leading to treatment discontinuation were reported in 10 (22.7\%) patients and none of the 30 reported deaths were considered to be treatment related.

In summary, the combination of necitumumab with $\mathrm{mFOL}$ FOX6 was associated with evidence of efficacy and a manageable safety profile in patients with previously untreated locally advanced or metastatic CRC. Clinical outcome was better in patients with KRAS exon 2 wild type compared with KRAS exon 2 mutant tumours. The efficacy of this combination appears to be at least comparable with other EGFR antibodies approved for use in combination with first-line oxaliplatin-based chemotherapy in patients with mCRC. Although cross-trial comparisons should be treated with caution, the data suggest that combining necitumumab with mFOLFOX6 has the potential to provide additional benefit in this setting. Further investigation of necitumumab with oxaliplatin-based chemotherapy in patients with tumours wild type for RAS is required if this EGFR $\mathrm{mAb}$ is to be added to the therapeutic armamentarium of mCRC.

\section{ACKNOWLEDGEMENTS}

We thank the patients, their families, and the study personnel across all sites for participating in this study. Paul Hoban of Cancer Communications and Consultancy Ltd, Knutsford, UK and Frank Ferrara of Eli Lilly and Company, Bridgewater, USA, provided writing assistance. Anastasia Perkowski of Eli Lilly and Company, Bridgewater, USA, provided editorial assistance. The study sponsor was Eli Lilly and Company. The study is registered with the European Union clinical trials register EudraCT number 2006-003147-23.

\section{CONFLICT OF INTEREST}

JS declared receiving honoraria from Lilly, Merck Serono, Roche, Amgen, Sanofi, and Bayer; and research funding from Merck Serono and Bayer. AC declared receiving honoraria from Lilly, Merck Serono, Roche, Amgen, and Bayer; and research funding from Roche, Merck Serono, and Bayer. AH declared receiving honoraria from Ipsen, Bayer, and Roche; and research funding from Bayer, Novartis, Roche, and Sirtex. RV, GC, and JW are employees of Eli Lilly and Company. JT declared consultant/ advisory board for Amgen, Boehringer Ingelheim, Celgene, Chugai, Imclone, Lilly, Merck, Merck Serono, Millennium, Sanofi, Symphogen, and Taiho. The remaining authors declare no conflict of interest.

\section{REFERENCES}

Amado RG, Wolf M, Peeters M, Van Cutsem E, Siena S, Freeman DJ, Juan T, Sikorski R, Suggs S, Radinsky R, Patterson SD, Chang DD (2008) 
Wild-type KRAS is required for panitumumab efficacy in patients with metastatic colorectal cancer. J Clin Oncol 26(10): 1626-1634.

Boccia RV, Cosgriff TM, Headley DL, Badarinath S, Dakhil SR (2010) A phase II trial of FOLFOX6 and cetuximab in the first-line treatment of patients with metastatic colorectal cancer. Clin Colorectal Cancer 9(2): 102-107.

Bokemeyer C, Bondarenko I, Hartmann JT, de Braud F, Schuch G, Zubel A, Celik I, Schlichting M, Koralewski P (2011) Efficacy according to biomarker status of cetuximab plus FOLFOX-4 as first-line treatment for metastatic colorectal cancer: the OPUS study. Ann Oncol 22(7): 1535-1546.

Bokemeyer C, Bondarenko I, Makhson A, Hartmann JT, Aparicio J, de Braud F, Donea S, Ludwig H, Schuch G, Stroh C, Loos AH, Zubel A, Koralewski P (2009) Fluorouracil, leucovorin, and oxaliplatin with and without cetuximab in the first-line treatment of metastatic colorectal cancer. J Clin Oncol 27(5): 663-671.

Bokemeyer C, Kohne CH, Ciardiello F, Lenz HJ, Heinemann V, Klinkhardt U, Beier F, Duecker K, van Krieken JH, Tejpar S (2015) FOLFOX4 plus cetuximab treatment and RAS mutations in colorectal cancer. Eur J Cancer 51: $1243-1252$.

Brodowicz T, Ciuleanu TE, Radosavljevic D, Shacham-Shmueli E, Vrbanec D, Plate S, Mrsic-Krmpotic Z, Dank M, Purkalne G, Messinger D, Zielinski CC (2013) FOLFOX4 plus cetuximab administered weekly or every second week in the first-line treatment of patients with KRAS wild-type metastatic colorectal cancer: a randomized phase II CECOG study. Ann Oncol 24(7): 1769-1777.

Chung KY, Shia J, Kemeny NE, Shah M, Schwartz GK, Tse A, Hamilton A, Pan D, Schrag D, Schwartz L, Klimstra DS, Fridman D, Kelsen DP, Saltz LB (2005) Cetuximab shows activity in colorectal cancer patients with tumors that do not express the epidermal growth factor receptor by immunohistochemistry. J Clin Oncol 23(9): 1803-1810.

Colucci G, Giuliani F, Garufi C, Mattioli R, Manzione L, Russo A, Lopez M, Parrella P, Tommasi S, Copetti M, Daniele B, Pisconti S, Tuveri G, Silvestris N, Maiello E (2010) Cetuximab plus FOLFOX-4 in untreated patients with advanced colorectal cancer: a Gruppo Oncologico dell'Italia Meridionale Multicenter phase II study. Oncology 79(5-6): $415-422$.

De Roock W, Piessevaux H, De Schutter J, Janssens M, De Hertogh G, Personeni N, Biesmans B, Van Laethem JL, Peeters M, Humblet Y, Van Cutsem E, Tejpar S (2008) KRAS wild-type state predicts survival and is associated to early radiological response in metastatic colorectal cancer treated with cetuximab. Ann Oncol 19(3): 508-515.

Di Fiore F, Blanchard F, Charbonnier F, Le Pessot F, Lamy A, Galais MP, Bastit L, Killian A, Sesboue R, Tuech JJ, Queuniet AM, Paillot B, Sabourin JC, Michot F, Michel P, Frebourg T (2007) Clinical relevance of KRAS mutation detection in metastatic colorectal cancer treated by Cetuximab plus chemotherapy. Br J Cancer 96(8): 1166-1169.

Douillard JY, Oliner KS, Siena S, Tabernero J, Burkes R, Barugel M, Humblet Y, Bodoky G, Cunningham D, Jassem J, Rivera F, Kocakova I, Ruff P, Blasinska-Morawiec M, Smakal M, Canon JL, Rother M, Williams R, Rong A, Wiezorek J, Sidhu R, Patterson SD (2013) Panitumumab-FOLFOX4 treatment and RAS mutations in colorectal cancer. N Engl J Med 369(11): 1023-1034.

Douillard JY, Siena S, Cassidy J, Tabernero J, Burkes R, Barugel M, Humblet Y, Bodoky G, Cunningham D, Jassem J, Rivera F, Kocakova I, Ruff P, Blasinska-Morawiec M, Smakal M, Canon JL, Rother M, Oliner KS, Tian Y, Xu F, Sidhu R (2014) Final results from PRIME: randomized phase III study of panitumumab with FOLFOX4 for first-line treatment of metastatic colorectal cancer. Ann Oncol 25(7): 1346-1355.

Douillard JY, Siena S, Cassidy J, Tabernero J, Burkes R, Barugel M, Humblet Y, Bodoky G, Cunningham D, Jassem J, Rivera F, Kocakova I, Ruff P, Blasinska-Morawiec M, Smakal M, Canon JL, Rother M, Oliner KS, Wolf M, Gansert J (2010) Randomized, phase III trial of panitumumab with infusional fluorouracil, leucovorin, and oxaliplatin (FOLFOX4) versus FOLFOX4 alone as first-line treatment in patients with previously untreated metastatic colorectal cancer: the PRIME study. J Clin Oncol 28(31): 4697-4705.

Ferlay J, Soerjomataram I I, Ervik M, Dikshit R, Eser S, Mathers C, Rebelo M, Parkin DM, Forman D, Bray F (2013) GLOBOCAN 2012 v1.0, Cancer Incidence and Mortality Worldwide: IARC CancerBase No. 11. Available at http://globocan.iarc.fr (accessed on 14 April 2015).
Folprecht G, Gruenberger T, Bechstein WO, Raab HR, Lordick F, Hartmann JT, Lang H, Frilling A, Stoehlmacher J, Weitz J, Konopke R, Stroszczynski C, Liersch T, Ockert D, Herrmann T, Goekkurt E, Parisi F, Kohne CH (2010) Tumour response and secondary resectability of colorectal liver metastases following neoadjuvant chemotherapy with cetuximab: the CELIM randomised phase 2 trial. Lancet Oncol 11(1): $38-47$.

Hochster HS, Hart LL, Ramanathan RK, Childs BH, Hainsworth JD, Cohn AL, Wong L, Fehrenbacher L, Abubakr Y, Saif MW, Schwartzberg L, Hedrick E (2008) Safety and efficacy of oxaliplatin and fluoropyrimidine regimens with or without bevacizumab as first-line treatment of metastatic colorectal cancer: results of the TREE study. J Clin Oncol 26(21): 3523-3529.

Karapetis CS, Khambata-Ford S, Jonker DJ, O'Callaghan CJ, Tu D, Tebbutt NC, Simes RJ, Chalchal H, Shapiro JD, Robitaille S, Price TJ, Shepherd L, Au HJ, Langer C, Moore MJ, Zalcberg JR (2008) K-ras mutations and benefit from cetuximab in advanced colorectal cancer. N Engl J Med 359(17): 1757-1765.

Kuenen B, Witteveen PO, Ruijter R, Giaccone G, Dontabhaktuni A, Fox F, Katz T, Youssoufian H, Zhu J, Rowinsky EK, Voest EE (2010) A phase I pharmacologic study of necitumumab (IMC-11F8), a fully human IgG1 monoclonal antibody directed against EGFR in patients with advanced solid malignancies. Clin Cancer Res 16(6): 1915-1923.

Licitra L, Storkel S, Kerr KM, Van Cutsem E, Pirker R, Hirsch FR, Vermorken JB, von Heydebreck A, Esser R, Celik I, Ciardiello F (2013) Predictive value of epidermal growth factor receptor expression for first-line chemotherapy plus cetuximab in patients with head and neck and colorectal cancer: analysis of data from the EXTREME and CRYSTAL studies. Eur J Cancer 49(6): 1161-1168.

Lievre A, Bachet JB, Boige V, Cayre A, Le Corre D, Buc E, Ychou M, Bouche O, Landi B, Louvet C, Andre T, Bibeau F, Diebold MD, Rougier P, Ducreux M, Tomasic G, Emile JF, Penault-Llorca F, Laurent-Puig P (2008) KRAS mutations as an independent prognostic factor in patients with advanced colorectal cancer treated with cetuximab. J Clin Oncol 26(3): 374-379.

Liu M, Zhang H, Jimenez X, Ludwig D, Witte L, Bohlen P, Hicklin DJ, Zhu Z (2004) Identification and characterization of a fully human antibody directed against epidermal growth factor receptor for cancer therapy. Cancer Res 64: 163.

Maughan TS, Adams RA, Smith CG, Meade AM, Seymour MT, Wilson RH, Idziaszczyk S, Harris R, Fisher D, Kenny SL, Kay E, Mitchell JK, Madi A, Jasani B, James MD, Bridgewater J, Kennedy MJ, Claes B, Lambrechts D, Kaplan R, Cheadle JP; MRC COIN Trial Investigators (2011) Addition of cetuximab to oxaliplatin-based first-line combination chemotherapy for treatment of advanced colorectal cancer: results of the randomised phase 3 MRC COIN trial. Lancet 377(9783): 2103-2114.

NCCN. Clinical practice guidelines in oncology (NCCN guidelines): colon cancer; Version 2.2015. Available at http://www.nccn.org/professionals/ physician_gls/pdf/colon.pdf (accessed 3 August 2015).

Ocvirk J, Brodowicz T, Wrba F, Ciuleanu TE, Kurteva G, Beslija S, Koza I, Papai Z, Messinger D, Yilmaz U, Faluhelyi Z, Yalcin S, Papamichael D, Wenczl M, Mrsic-Krmpotic Z, Shacham-Shmueli E, Vrbanec D, Esser R, Scheithauer W, Zielinski CC (2010) Cetuximab plus FOLFOX6 or FOLFIRI in metastatic colorectal cancer: CECOG trial. World $J$ Gastroenterol 16(25): 3133-3143.

Petrelli F, Cabiddu M, Borgonovo K, Barni S (2012) Risk of venous and arterial thromboembolic events associated with anti-EGFR agents: a metaanalysis of randomized clinical trials. Ann Oncol 23(7): 1672-1679.

Prewett M, Tonra JR, Rajiv B, Hooper AT, Makhoul G, Finnerty B, Witte L, Bohlen P, Zhu Z, Hicklin DJ (2004) Antitumor activity of a novel, human anti-epidermal growth factor receptor (EGFR) monoclonal antibody (IMC-11F8) in human tumor xenograft models. Proc Am Soc Clin Oncol 45: Abstract 5353.

Tabernero J, Van Cutsem E, Diaz-Rubio E, Cervantes A, Humblet Y, Andre T, Van Laethem JL, Soulie P, Casado E, Verslype C, Valera JS, Tortora G, Ciardiello F, Kisker O, de Gramont A (2007) Phase II trial of cetuximab in combination with fluorouracil, leucovorin, and oxaliplatin in the first-line treatment of metastatic colorectal cancer. J Clin Oncol 25(33): $5225-5232$.

Therasse P, Arbuck SG, Eisenhauer EA, Wanders J, Kaplan RS, Rubinstein L, Verweij J, Van Glabbeke M, van Oosterom AT, Christian MC, Gwyther SG (2000) New guidelines to evaluate the response to treatment in solid tumors. European Organization for 
Research and Treatment of Cancer, National Cancer Institute of the United States, National Cancer Institute of Canada. J Natl Cancer Inst 92(3): 205-216.

Van Cutsem E, Cervantes A, Nordlinger B, Arnold D; ESMO Guidelines Working Group (2014) Metastatic colorectal cancer: ESMO Clinical Practice Guidelines for diagnosis, treatment and follow-up. Ann Oncol 25(Suppl 3): iii1-iii9.

Van Cutsem E, Kohne CH, Lang I, Folprecht G, Nowacki MP, Cascinu S, Shchepotin I, Maurel J, Cunningham D, Tejpar S, Schlichting M, Zubel A, Celik I, Rougier P, Ciardiello F (2011) Cetuximab plus irinotecan, fluorouracil, and leucovorin as first-line treatment for metastatic colorectal cancer: updated analysis of overall survival according to tumor KRAS and BRAF mutation status. J Clin Oncol 29(15): 2011-2019.

Venook A, Niedzwiecki D, Hollis D, Sutherland S, Goldberg R, Alberts S, Benson A, Wade J, Schilsky R, Mayer R (2006) Phase III study of irinotecan/5FU/LV (FOLFIRI) or oxaliplatin/5FU/LV
(FOLFOX) \pm cetuximab for patients (pts) with untreated metastatic adenocarcinoma of the colon or rectum (MCRC): CALGB 80203 preliminary results. J Clin Oncol 24(18S): Abstract 3509.

Wasan H, Meade AM, Adams R, Wilson R, Pugh C, Fisher D, Sydes B, Madi A, Sizer B, Lowdell C, Middleton G, Butler R, Kaplan R, Maughan T (2014) Intermittent chemotherapy plus either intermittent or continuous cetuximab for first-line treatment of patients with KRAS wild-type advanced colorectal cancer (COIN-B): a randomised phase 2 trial. Lancet Oncol 15(6): 631-639.

\section{(c) (P) This work is licensed under the Creative Commons Attribution 4.0 International License. To view a copy of this license, visit http://creativecommons.org/ licenses/by/4.0/}

Supplementary Information accompanies this paper on British Journal of Cancer website (http://www.nature.com/bjc) 